\title{
Analysis for the Defect of Chromatogram in 35kv Oil-immersed Electric Reactor
}

\author{
Yongdong Li, Qingda Meng, Zheyuan Zhao, Po Yang, Yuzheng Wang \\ Maintenance of northern Hebei Province Electric Power Co. Ltd, Substation maintenance center, Beijing, China \\ Email: zhaozy447525200@126.com
}

Received April, 2013

\begin{abstract}
A defect of chromatogram in a $35 \mathrm{kV}$ oil-immersed three-phase one-piece electric reactor has been found in a $500 \mathrm{kV}$ substation. The initial analysis suggests that the defect is caused by the loose connection of the iron core magnet shield (magnet shield layer of iron core or earthling top). Examination of winding DC resistance, DGA and other relevant examinations were carried out to investigate the defect reasons, which is demonstrated by the dismantlement. In-depth study is taken and corresponding prevention measures are put forward in the paper.
\end{abstract}

Keywords: Oil-immersed Electric Reactor; Chromatogram Defect; Magnet Shield Layer; Partial Discharge

\section{Introduction}

$35 \mathrm{kV}$ shunt reactor is suitable for the high voltage parallel circuit of $35 \mathrm{kV}$ power system and high-speed rail power supply system. It transfers perceptual reactive power to system through the main transformer, prevents the voltage of light load from increasing and maintains the voltage stability of the power transmission system. It increases the saving energy and power factor of the electric power system. As the additional compensation equipment for the power system stabilization, it plays an important role in adjusting the power grid, affecting the safe and stable operation of power grid [1]. Oil-immersed reactor has gradually been widely used because of its running stability, low dissipation, small floor, no leakage pollution, free maintenance function and so on.

\section{Failure Analysis}

On April 20, 2012, Reactor insulation oil chromatographic experiments of the $500 \mathrm{kV}$ substation of changping 321 shows the acetylene content is $128.1 \mu \mathrm{L} / \mathrm{L}$, the hydrogen content is $259.8 \mu \mathrm{L} / \mathrm{L}$, beyond the rules, rapid growth in acetylene content. On April 21, 2012 this reactor was out of service. This reactor is Oil-immersed self-cooled reactor and its factors: Japan's nissin production motor co., LTD. Nominal voltage: $35 \mathrm{kV}$, Rated capacity: 30 MVA, Model: RMO-VCA, Date of production: June 1995, Put into operation date: December 10th, 1995; Equipment running time: nearly 17 years.

Since 2005 , as the aging problems, the total hydrocarbon content of this reactor is always over proof. (regulation value is $150 \mathrm{ul} / \mathrm{l}$ ), the data of the test oil chroma- togram shows in Table 1.

On 20th April, 2012, in the experiment of oil chromatographic, there is a large amount of $\mathrm{H}_{2}$ and $\mathrm{C}_{2} \mathrm{H}_{2}$ in the oil. According to use of the three-ratio method in standards, it plays an important role which is elaborated in the diagnosis of actual failures of the transformer, electric reactor, oil-filled electrical equipments and related equipments. The result of oil chromatographic analysis and calculation is shown below in the Table 2[3,4].

Table 1. Oil chromatographic data.

\begin{tabular}{cccccccccc}
\hline $\mathrm{H}_{2}$ & $\mathrm{CH}_{4}$ & $\mathrm{C}_{2} \mathrm{H}_{6}$ & $\mathrm{C}_{2} \mathrm{H}_{4}$ & $\mathrm{C}_{2} \mathrm{H}_{2}$ & $\mathrm{CO}$ & $\mathrm{CO}_{2}$ & $\begin{array}{c}\text { hydrocarbon } \\
\text { content }\end{array}$ & $\begin{array}{c}\text { Test } \\
\text { date }\end{array}$ \\
\hline 1 & 32.5 & 113.3 & 3 & 0 & 78.2 & 768.9 & 148.8 & 2005.7 .7 \\
1.1 & 41.4 & 118.3 & 4 & 0 & 115.4 & 801.4 & 163.7 & 2006.1 .5 \\
2.7 & 47.8 & 127.9 & 4.1 & 0 & 119.6 & 732.1 & 179.7 & 2007.4 .3 \\
1.4 & 50 & 143.8 & 4.5 & 0 & 109.9 & 865.9 & 198.3 & 2008.4 .10 \\
1.5 & 51.8 & 169.9 & 4.9 & 0 & 111.4 & 1035.8 & 226.6 & 2009.4 .10 \\
1.4 & 56.5 & 150.6 & 4.8 & 0 & 113.6 & 902.8 & 211.9 & 2010.2 .2 \\
1.4 & 61.5 & 163.1 & 5.5 & 0 & 117.9 & 826.2 & 230.1 & 2011.1 .20 \\
1.1 & 54.8 & 150 & 5.5 & 0 & 107.3 & 874.8 & 210.3 & 2011.7 .27 \\
2.4 & 62.3 & 183.8 & 6.5 & 0 & 113.9 & 986.6 & 252.6 & 2011.10 .20 \\
259.8 & 71.9 & 181 & 23.9 & 128.1 & 109.1 & 886.5 & 404.9 & 2012.4 .20
\end{tabular}


Table 2. Calculated data with three-radio method.

\begin{tabular}{ccc}
\hline $\mathrm{C}_{2} \mathrm{H}_{2} / \mathrm{C}_{2} \mathrm{H}_{4}$ & $\mathrm{CH}_{4} / \mathrm{H}_{2}$ & $\mathrm{C}_{2} \mathrm{H}_{4} / \mathrm{C}_{2} \mathrm{H}_{6}$ \\
\hline 5.360 & 0.277 & 0.132 \\
\hline
\end{tabular}

The encoding of the three-ratio method is 2,0 and 0. According to preliminary inspection, it is low energy discharging which may be caused by spark discharge in oil between potential difference or spark discharge between floating potential [5].

Nissin electric co., LTD and we made an initial evaluated depending on standards values which are stipulated by Electrical collaborative research, gas anomaly diagnosis diagrams and characteristic of the gas analysis as shown below:

1) As the absolute value of the $\mathrm{CO}$ content is below the standards value of $300 \mathrm{ppm}, \mathrm{CO}_{2} / \mathrm{CO}=8.1>3$ and the phenomenon of increasing of $\mathrm{CO}$ content caused by overheating of the insulating is never happened, the possibility is very low which is the wind and insulating is overheating in sudden. In addition, it takes a high risk that the failure is may happened around the insulating.

2) In general, when the equipment is overheating suddenly $\left(\mathrm{C}_{2} \mathrm{H}_{2} / \mathrm{C}_{2} \mathrm{H}_{4} \leqq 0.2\right)$, but the defect $\mathrm{C}_{2} \mathrm{H}_{2} / \mathrm{C}_{2} \mathrm{H}_{4}=5.3$ $>0.2$ here, this reason can be considered as partial discharge in the low energy area.

3) The value of acetylene $\left(\mathrm{C}_{2} \mathrm{H}_{2}\right)$ content (128.1 ppm)is far beyond the evaluation abnormal value $(5 \mathrm{ppm})$ which is written by the book of "maintenance management of oil immersed transformer" in Japan. The partial discharge leads to the increasing of $\left(\mathrm{C}_{2} \mathrm{H}_{2}\right)$.

In accordance with the analysis of the results above, it can be estimated that the rise of $\mathrm{C}_{2} \mathrm{H}_{2}$ content and $\mathrm{H}_{2}$ content is caused by that partial discharge is happened in the part of bare metal of surrounding insulating (Core or the magnetic shielding grounding side).

\section{Inspection of the Equipment Disintegration}

Electric reactor should be dismasted and disintegrated to check in the factory.

1) Check and test in the factory

When the equipment returning to the factory, it should take a test and measure in Reactor winding dc resistance of ontology, insulation, reactance, consume, spilt ratio and so on. Compared with the result of acceptance test of elector equipment, the experimental result is normal.

2) Introduction of disintegration

As this reactor is integrated structure, the component is not removed. Bottom of reactor can't be cut. The test of disintegration should be taken by cutting the bottom of the reactor. The structure is shown below as Figure 1.

When testing the A core magnetic shielding, we find out that around the Aluminum foil stickers, it appeared the discharge stains on the top of the seventh layer and the eighth layer, the bottom of the eighth layer and the ninth layer of A core magnetic shielding. The flowchart of dismantling the reactor is shown below as Figure 2.

The aluminum foil and the grounding potential separation of copper is shown as below in Figure 3.

\section{Failure Confirm}

According to the state of equipment disintegration, we know that the cause of failure is:

1) The shape of shielding copper in the core magnetic shielding is banding, both sides of it is fixed on the aluminum foil. In the long running process, as the repeating operation of reactor, the winding vibration results in the contact area of aluminum foil and copper board endures the stress. The contact area of aluminum foil and copper board adopts the manual welding, affecting by the human factors. When the stress is applied to this area, the contact of aluminum foil and copper board will be broken and produce the floating electrode.

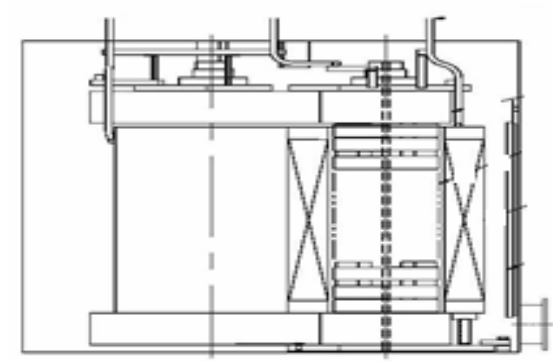

Figrue 1. Diagram of inner structure of the reactor.

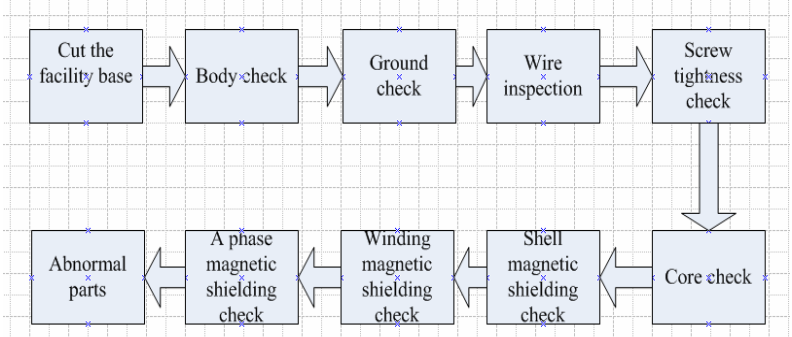

Figure 2. Flowchart of dismantling the reactor.
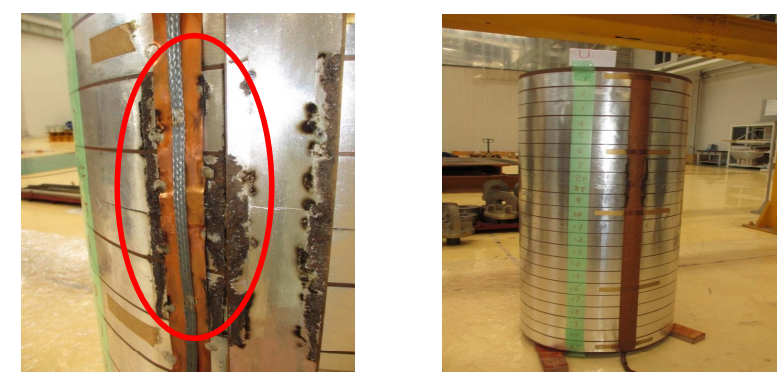

Figure 3. Photo of discharge trace of magnet shield layer. 
The potential difference between floating electrode and grounding copper plate will discharge, results in a large number of characteristic gas $\left(\mathrm{H}_{2}\right.$, acetylene).[7]

2) According to the site situation, we use the simulated calculation to describe the electric field distribution of this area. (Figure 4) as we can see from the Figure 4, the electric field intensity of the broken area between the aluminum foil and copper board is the highest. So the characteristic gas is produced by the electric discharge.

\section{Process Improvement and Troubleshooting}

\subsection{Process Improvement}

Now we improve the original welding process from the manual welding to the mechanical pressure welding. This method decreases the manual factors of the production process. The comparison of production process shows below:(Figure 5)

\subsection{Fault Handling}

\subsubsection{Core Magnetic Shield Operation Process}

1) Shearing the aluminum foil according to the design value.

(2) Welding Braided wire on the cooper board. (Figure 6)

3) Pressure welding the aluminum foil and cooper board by the welding spot.(Figure 7)

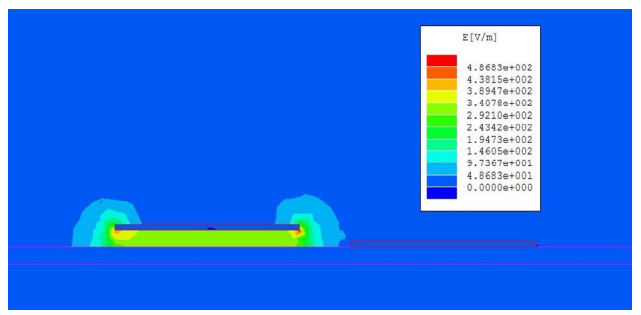

Figure 4. Suspension electric field strength of aluminum foil.
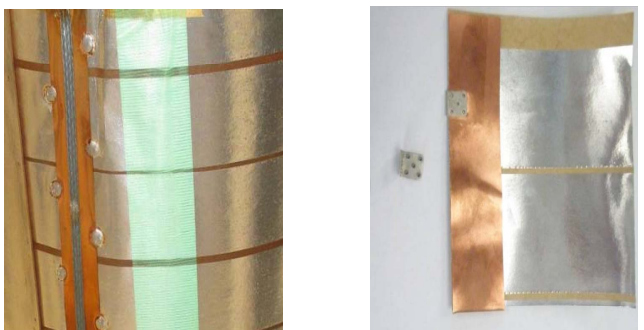

Figure 5. Photo of contrast between before and after the improvement.

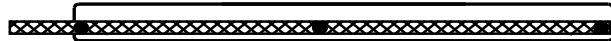

Figure 6. Process of Core magnet shielding.

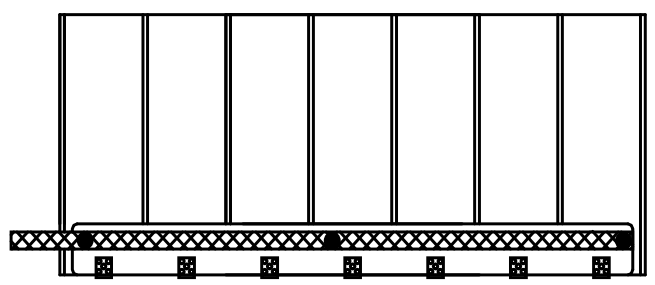

Figure 7. Process of Core magnet shielding.

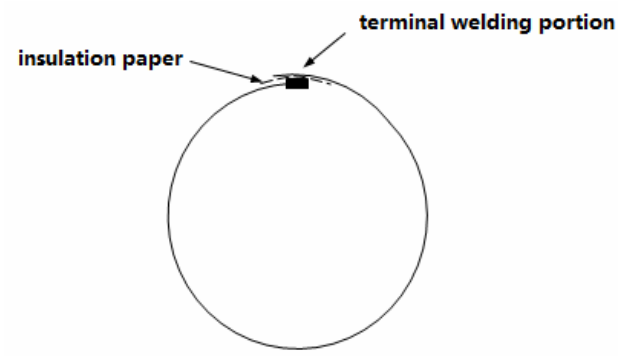

Figure 8. Process of Core magnet shielding.

4) Making sure there is no space between the pressure welding spots. Both five gears between the spots must be corresponding. Using the aluminum foil stickers to roll on the insulating cylinder. This prevents it from the loop current. The whole process shows below:(Figure 8)

\subsubsection{The Spare Parts Replacement and Factory Test}

We replace the old reactor seal ring, valve, thermometer and gas capsule by the new one and then spray new paint.

According to the factory test, the experiment required standard is: measurement of winding resistance, measurement of dielectric loss as well as electrostatic capacity, reactance test, loss measurement, noise test, measurement of insulation resistance, withstand voltage test, partial discharge test, BCT test, temperature rise test, gas analysis and all the experiment data is in the normal range.

\section{Conclusions}

The main reason that this equipment is on failure is caused by aluminum foil stickers on core magnetic shielding and open wild of contact area of copper board. This reactor should be repaired well. The issue also should be paid attention as such problems. What's more, the ways to improve it should be summed up as well. It's essential to take preventive actions when such problems happen. There some suggestions to improve it as shown below:

1) We can quickly make a judgment about failure reason if the same type of this kind of products is in the such situation. There is a better way to improve the efficiency of maintenance.

2) When such product is on the design period, we 
should consider sufficiently that processing craft of the part which need to be connected tightly and take the right measurement of soldering.

3) For such same type products in the same factory which have been already put into operation, the ways which are core magnetic shielding of manual welding process. we should pay a high attention about the status of operation. When such problems are happened, we should report without delay and return it for repairing in factory to avoid increasing the risk if necessary.

\section{REFERENCES}

[1] Joon-Ho Choi, Jae-Chul Kim. Advanced Voltage Regulation Method at the Power Distribution Systems Interconnected with Dispersed Storage and Generation Systems. IEEE Transactions on Power Delivery, Vol. 15, No. 2, 2000, pp. 691-696.

[2] M. A. Farrag, M. M. El-Metwally and M. S. El-Bages, "New Model for Distribution System Planning," International Journal of Electrical
Power and Energy System, Vol. 21, No. 7, 1999, pp. 523-531.

[3] G. Celli and F. Pilo, "MV Network Planning Under Uncertainties on Distributed Generation Penetration," IEEE power Engineering Society Summer Meeting. 2001.

[4] B. F. Hampton and R. J. Meats, "Diagnostic Measurement at Pt. C, in gas insulated substations, IEE Proceedings, Vol. 135, No. 2, 1988, pp. $137-145$

[5] IEC60071-2, Insulation Coordination, Part 2, Application Guide, IEC Publication, 1996.

[6] R. Bozzo, F. Guastavina, G. guema, "PD Detection and Localization by Means of Acoustic Measurements on Hydrogenerator Stator Bars," IEEE Transactions on Dielectrics and Electrical Insulation, Vol. 2, No. 4, 1995, pp. 660-666.

[7] G. B. Nicholas, "Papadopoulos Michael P. Optimal Feeder Routing in Distribution System Planning Using Dynamic Programming Technique and Gis Facilities," IEEE Transactions on Power Delivery, 2002, Vol. 17, No. 1, pp. 242-247. 